\title{
High cell density fed-batch production of insecticidal recombinant ribotoxin hirsutellin A from Pichia pastoris
}

Hongbo Li ${ }^{1,2}$ and Yuxian Xia ${ }^{1,3^{*}}$

\begin{abstract}
Background: The fungal ribotoxin hirsutellin A $(\mathrm{HtA})$ exhibits strong insecticidal activity; however, efficient systems for expressing recombinant $\mathrm{HtA}(\mathrm{rHtA})$ are lacking. Here, we established an efficient heterologous expression system to produce large amounts of $\mathrm{rHtA}$.

Results: Recombinant Pichia pastoris transformants with high levels of secretory $\mathrm{rHtA}$ were screened, and in a fedbatch reactor, $\mathrm{rHtA}$ was secreted at levels up to $80 \mathrm{mg} / \mathrm{l}$ following methanol induction, which was more than sixfold higher than that in shake flasks. Approximately $7 \mathrm{mg}$ of highly pure rHtA was obtained from $300 \mathrm{ml}$ of fed-batch culture supernatant by $\mathrm{Ni}^{+}$-nitriloacetic acid affinity chromatography and CM Sepharose ion-exchange chromatography. Mass spectrometry results revealed $\mathrm{rHtA}$ as a native $\mathrm{N}$-terminal non-glycosylated monomeric protein with a molecular weight of $15.3 \mathrm{kDa}$. Purified rHtA exhibited excellent thermal and protease stability and dose-dependent cytotoxicity to Sf9 insect cells and insecticidal activity against Galleria mellonella larvae.
\end{abstract}

Conclusions: This is the first report of $\mathrm{rHtA}$ expression in P. pastoris. The rHtA was expressed at a high level under high-cell-density fed-batch fermentation and was efficiently purified using a two-step purification method. Purified rHtA exhibited thermal and protease stability, as well as appropriate bioactivities. Our results indicate that fed-batch production by $P$. pastoris is an efficient method to produce functional $r \mathrm{HtA}$.

Keywords: Ribotoxin, Hirsutellin A, Pichia pastoris, Fed-batch, Purification

\section{Background}

Chemical pesticides are widely used. However, the extensive use of these pesticides also affects non-target insects and animals, thereby impairing ecosystem, potentially posing a risk to human health, and causing diseases, including cancer, reproductive disorders, neurological disorders, and allergies. Therefore, there is a consensus to reduce the use of pesticides [1]. To better protect the ecological environment and human health, and to maintain sustainable agricultural development, it is urgent to develop "green" pesticides [2-5]. Fungi are the major source of biological pesticides [6-8]. Their metabolites,

\footnotetext{
*Correspondence: yuxianxia@cqu.edu.cn

${ }^{3}$ Genetic Engineering Research Center, College of Life Sciences, Chongqing University, No. 55 South Road of University Town, Shapingba District, Chongqing 401331, China

Full list of author information is available at the end of the article
}

including toxic proteins and peptides, have the potential to be used in biological pest control [9-11].

Ribotoxins produced by some fungal species, such as Aspergillus, Hirsutella thompsonii and other entomopathogenic fungi, have the potential to be used as biological pesticides $[10,12,13]$. Specifically, the fungal ribotoxin hirsutellin A (HtA) produced by the invertebrate fungal pathogen $H$. thompsonii exhibits insect-specific cytotoxicity and strong insecticidal properties [14, 15]. Native HtA is a non-glycosylated monomeric protein comprising 130 amino acid residues and shows thermo stability and protease stability. As a comparison, HtA is 10-20 amino acids shorter than ribotoxins from Aspergillus, and has a low homology with them (25\%), which is the main reason leading to significant differences in their biological functions [14, 16, 17]. Previous studies have reported that HtA is highly toxic to adult mites and 
aphids, lethal to moth and fly larvae, and shows oral toxicity to neonatal larvae of Aedes aegypti $[14,15]$. However, the content of native HtA is low, with only $35 \mu \mathrm{g}$ $\mathrm{HtA}$ isolated from the supernatant of $1 \mathrm{~g}$ of dried mycelium and less than $1 \mathrm{mg} H \mathrm{HtA}$ purified from $1 \mathrm{l}$ of fermentation broth [14]. Although recombinant HtA (rHtA) has been successfully prepared using Escherichia coli (E. coli) expression system, less than $1 \mathrm{mg}$ rHtA could be purified from $1 \mathrm{l}$ of culture medium using a complex purification protocol [12]. Moreover, E. coli-expressed rHtA is not the $\mathrm{N}$-terminal native protein, resulting in potentially different biological activity. Additionally, E. coli produces large amounts of endotoxin, which needs to be removed before in vivo activity analyses. The failure to prepare large amounts of HtA has seriously limited the further development of its insecticidal potential.

Investigation of $\mathrm{HtA}$ bioactivity against insect pests requires large quantities of protein [14, 15]. In particular, the determination of the oral insecticidal activity of $\mathrm{HtA}$ against agricultural pests and its biological safety to mammals also requires a large amount of protein $[14,15]$. Therefore, it is necessary to develop a heterologous protein expression system and efficient purification method to prepare a large amount of active rHtA. As a widely used high-level eukaryotic protein-expression system, Pichia pastoris (P. pastoris) has the ability to secrete recombinant proteins [18]. Additionally, $P$. pastoris has the ability to produce gram-level amounts of secretory recombinant protein per litre of fermentation culture [19]. Furthermore, P. pastoris does not produce endotoxin. Therefore, purified recombinant proteins can be directly used for in vivo experiments.

In this study, we reported a method for efficient expression and purification of rHtA from P. pastoris X33 by fedbatch fermentation. Also, we analysed the bioactivity of rHtA.

\section{Results \\ Plasmid construction and selection of $P$. pastoris transformants}

Following a 72-h incubation at $28^{\circ} \mathrm{C}$, single colonies from YPD plates containing $1 \mathrm{mg} / \mathrm{ml}$ zeocin were picked and amplified by PCR. A fragment of $\sim 400$ bp was generated, suggesting integration of the pPICZ $\alpha \mathrm{A}-H t A$ plasmid into the $P$. pastoris genome (data not shown). Based on the amino acid sequence of $\mathrm{rHtA}$, the theoretical MW of rHtA was $\sim 15 \mathrm{kDa}$ according to Expasy prediction (http://www.expasy.ch/cgi-bin/pi_tool). SDS-PAGE results for all screened transformants (Fig. 1a) indicated their ability to secrete a protein with a MW similar to that predicted for rHtA, whereas control transformants $(\mathrm{pPICZ} \alpha \mathrm{A})$ and samples from the untransformed X33 strain showed no visible protein band at the predicted MW. Among these transformants, the transformant in a

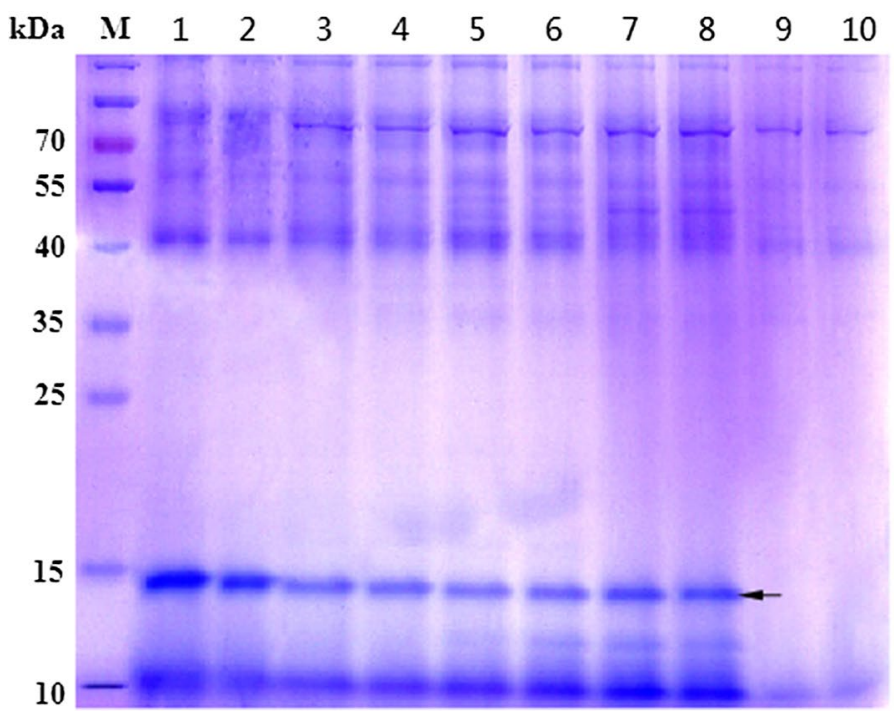

b Methanol induction time (d)

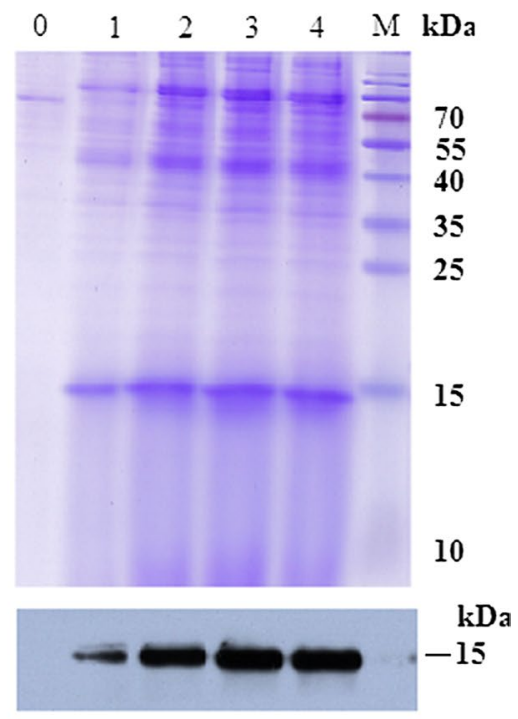

Fig. 1 Detection of rHtA expression. a SDS-PAGE analysis of secreted rHtA transformants. Lanes 1-8, BMMY culture supernatant of selected transformants from $1 \mathrm{~g} / \mathrm{I}$ zeocin YPD plates; lane 9, BMMY culture supernatant of the untransformed X33 strain; lane 10, BMMY culture supernatant of empty vector transformants; lane M, protein marker. The expressed rHtA was marked with an arrow. b SDS-PAGE and western blot analysis of rHtA. Culture supernatant was collected at the indicated time (0, 1,2,3 and 4 days) after methanol induction in flasks. Precipitation was initiated using final concentration of 10\% TCA, and proteins were analysed by 15\% SDS-PAGE and stained with Coomassie Brilliant Blue R250. Lane M, protein marker 
Lane 1 had the highest level of rHtA expression and fewer contaminated proteins. Thus, this transformant was used for the following high cell density fermentation. These results showed that the pPICZ $\alpha \mathrm{A}-\mathrm{HtA}$ plasmid was successfully constructed and could produce secreted rHtA in the $P$. pastoris X33 strain.

\section{Time course of rHtA expression in shake flasks}

We detected a protein at $\sim 15 \mathrm{kDa}$ by SDS-PAGE following a 1-day methanol induction (Fig. 1b). The protein content reached a maximum level at 3 days of methanol induction. However, the proportion of rHtA did not significantly increase along with increased induction time after 3 days. At 3-days post-induction, the band for rHtA equated to $\sim 3 \mu \mathrm{g}$, suggesting that the concentration of secreted $\mathrm{rHtA}$ was $\sim 13 \mathrm{mg} / \mathrm{l}$ in the media. Western blot results confirmed that the recombinant protein was rHtA, and that the highest level of rHtA was obtained after 3 days of methanol induction (Fig. 1b).

\section{Fed-batch fermentation}

Glycerol fed-batch culture was initiated after the initial glycerol was exhausted based on increased dissolved oxygen (DO) levels and decreased stirring. During this phase of biomass increase, highest biomass level was achieved at a feed-solution flow rate of $24 \mathrm{ml} / \mathrm{h}$, with the wet weight of $P$. pastoris cells reaching $390 \mathrm{~g} / \mathrm{l}$ before the addition of methanol. Within $12 \mathrm{~h}$ after the addition of methanol, cell density declined, indicating that the change in carbon source significantly inhibited the growth of yeast. With the adaptation of $P$. pastoris to methanol, the yeast began to grow slowly, and the wet weight of the cells reached $\sim 440 \mathrm{~g} / \mathrm{l}$ by the end of fermentation (Fig. 2a). During fed-batch fermentation, rHtA secretion was detected at 12-h post-methanol induction, with secreted $\mathrm{rHtA}$ reaching a peak at $\sim 60$ to $\sim 72 \mathrm{~h}$ after the addition of methanol. However, prolonging the induction time resulted in decreases in rHtA content (Fig. 2b). Western blot results confirmed that that the highest rHtA concentration was obtained at 72-h post-induction. Gel-scanning results indicated an rHtA concentration of $\sim 78 \mathrm{mg} / \mathrm{l}$ in fedbatch supernatant at 72-h post-induction (Fig. 2c), which was more than sixfold higher than that in shake flasks ( $\sim 13 \mathrm{mg} / \mathrm{l}$; Fig. 1b). These results demonstrate that high cell-density culture of $P$. pastoris offers high productivity of rHtA in the bioreactor.

\section{Purification of rHtA}

Recombinant $\mathrm{HtA}$ was able to bind to $\mathrm{Ni}^{+}-\mathrm{NTA}$ resin (Fig. 3a). After washing with buffer containing $30 \mathrm{mM}$ imidazole, protein contaminants were removed, and at $50 \mathrm{mM}$ imidazole, small amounts of rHtA began to elute, with rHtA elution increasing along with imidazole concentrations up to $500 \mathrm{mM}$. Approximately $12.3 \mathrm{mg}$ rHtA was obtained from 300-ml fed-batch supernatant by $\mathrm{Ni}^{+}$-NTA affinity purification, equivalent to a $\sim 61 \%$ recovery rate. The eluted samples from the $\mathrm{Ni}^{+}-\mathrm{NTA}$ column showed a single protein band, whereas contaminated proteins became visible following concentration of the samples by sevenfold (Fig. 3b). After dialysis, the rHtA solution was subjected to $\mathrm{CM}$ ion-exchange chromatography (Fig. 3c), resulting in a single protein
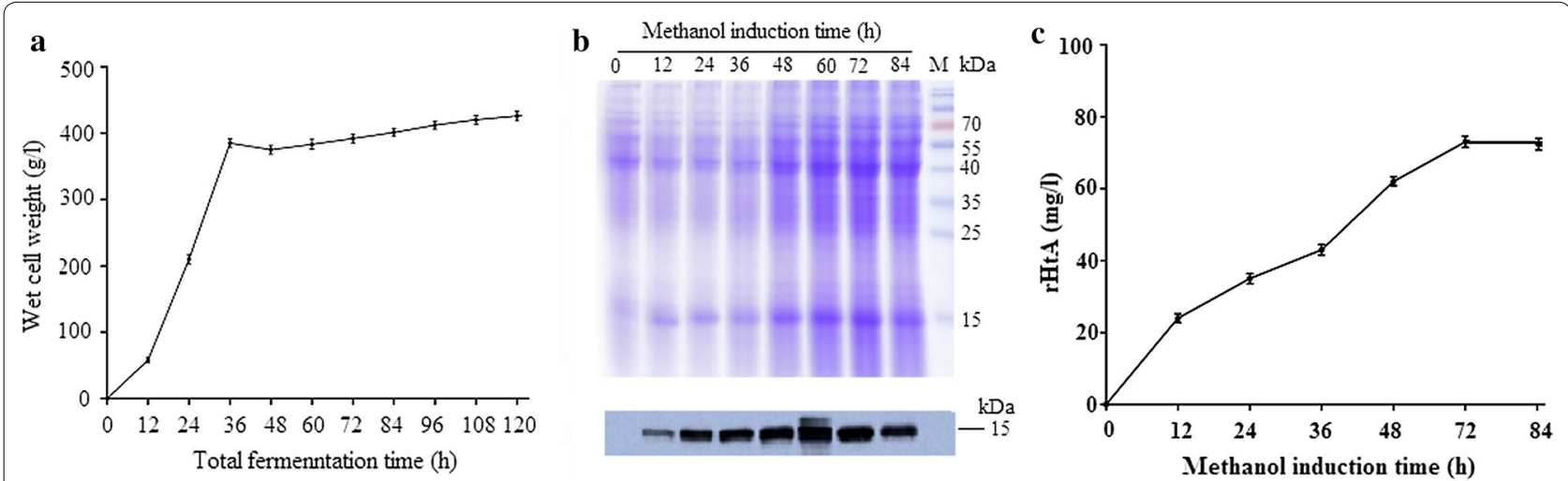

Fig. 2 Analysis of $\mathrm{rHtA}$ expression under fermentation conditions. a Time course of changes in wet-cell weight in a 5-l bioreactor. Cells were collected at the indicated times. The wet weight of cultured cells was obtained by centrifugation at $16000 \mathrm{~g}$ for $15 \mathrm{~min}$ at $4{ }^{\circ} \mathrm{C}$. b SDS-PAGE analysis of the time course associated with rHtA expression in the 5-I bioreactor. Culture supernatant was collected at the indicated times after methanol induction. Protein concentration in the supernatant was determined by Bradford assay, and BSA was used as the standard. c Detection of $\mathrm{rHtA}$ concentration by gel scanning. Culture supernatant was collected th the indicated times after methanol induction. The supernatants were precipitated, then analyzed on 15\% SDS-PAGE and stained with Coomassie blue R250. After the decolorization, the protein imaging system scanned the SDS-PAGE gel. The gray scale of the protein strip was analyzed by Quantity One software (Bio-Rad) and the concentrations of target bands were calculated 
a

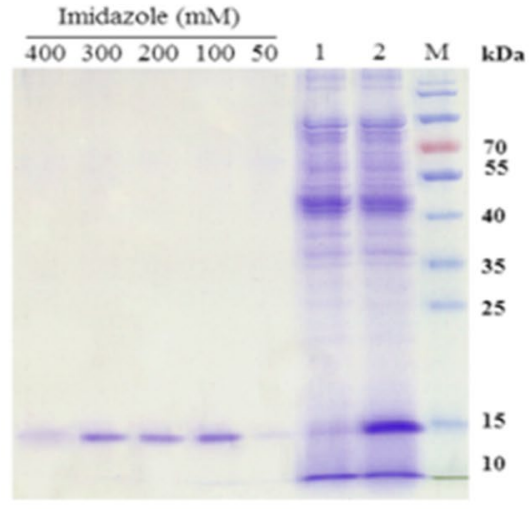

b

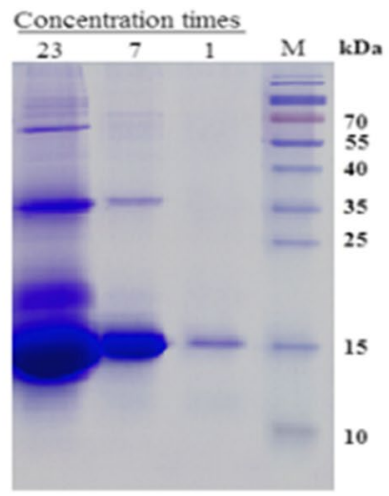

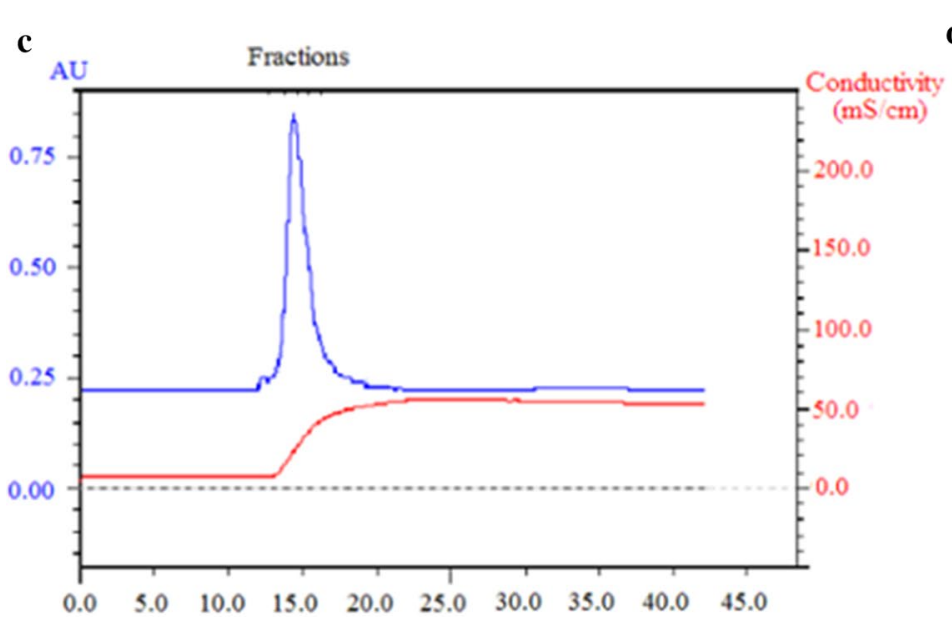

d

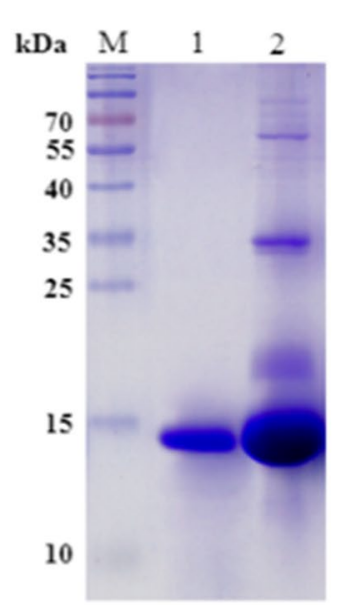

e

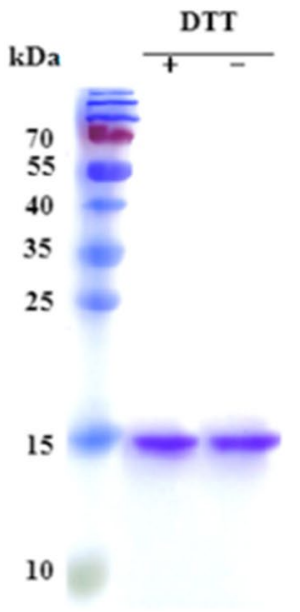

Fig. 3 Purification of $\mathrm{rHtA}$. a Purification of $\mathrm{rHtA}$ by $\mathrm{Ni}^{+}-\mathrm{NTA}$ chromatography. Lane 1, elution sample following loading; lane 2, elution prior to purification. b Analysis of concentrated $\mathrm{rHtA}$ purity following $\mathrm{Ni}^{+}{ }^{-} \mathrm{NTA}$ purification. Lane 23, 23-fold concentration; lane 7, sevenfold concentration; lane 8, eluted rHtA (unconcentrated); lane M, protein marker. c Elution curves of $\mathrm{rHtA}$ by ion-exchange chromatography. The eluents were collected according to $\mathrm{OD}_{280 \mathrm{~nm}}>250 \mathrm{mAU}$. The blue curve and the red curve represent the $\mathrm{UV}$ absorbance $(\mathrm{mAU})$ and ionic strength $(\mathrm{mS} / \mathrm{cm})$ of the eluent, respectively. $\mathbf{d}$ SDS-PAGE analysis (15\%) of rHtA by ion-exchange chromatography. Lane 1, eluted rHtA; lane 2, 23-fold concentration of the eluent from the $\mathrm{Ni}^{+}$-NTA column; lane M, protein marker. e SDS-PAGE analysis of concentrated rHtA by ion-exchange chromatography under reducing and non-reducing conditions. Lane 1, reduced conditions; lane 2, non-reducing conditions; lane M, protein marker

Table 1 Purification of rHtA from the fed-batch ferment supernatant

\begin{tabular}{llll}
\hline Purification steps & $\begin{array}{l}\text { Total } \\
\text { volume } \\
(\mathbf{m l})\end{array}$ & rHtA (mg) & Recovery (\%) \\
\hline Supernatant before purification & 300 & 20.2 & 100 \\
$\mathrm{Ni}^{+}$affinity chromatography & 100 & 12.3 & 61 \\
$\mathrm{CM}$ chromatography & 4.1 & 6.9 & 34 \\
\hline
\end{tabular}

peak, following elimination of the contaminating proteins (Fig. 3d). Following this step, acquisition of $\sim 7 \mathrm{mg}$ pure rHtA with a $\sim 34 \%$ recovery rate was yielded from $300 \mathrm{ml}$ of crude culture supernatant, with a purity of up to $95 \%$ (Table 1). Under both reducing and non-reducing conditions, SDS-PAGE analysis revealed a single band for purified rHtA (Fig. 3e), indicating that rHtA was a monomeric protein expressed in $P$. pastoris. These results indicate that high purity rHtA could be prepared by $\mathrm{Ni}^{+}$-NTA affinity purification and $\mathrm{CM}$ ion-exchange chromatography.

\section{Determination of $\mathrm{rHtA} \mathrm{MW}$ and amino acid sequence}

MW determination by Q-TOF-MS showed that the average MW of purified rHtA was $15.304 \mathrm{kDa}$ (Fig. 4), which was similar to the theoretical MW $(\sim 15.308 \mathrm{kDa})$, suggesting that purified rHtA from P. pastoris is a non-glycosylated protein. Nano-LC-MS/MS results identified 34 peptides (Table 2) matching the 136 amino acids in the sequence of full-length rHtA. LC-MS/MS results verified 


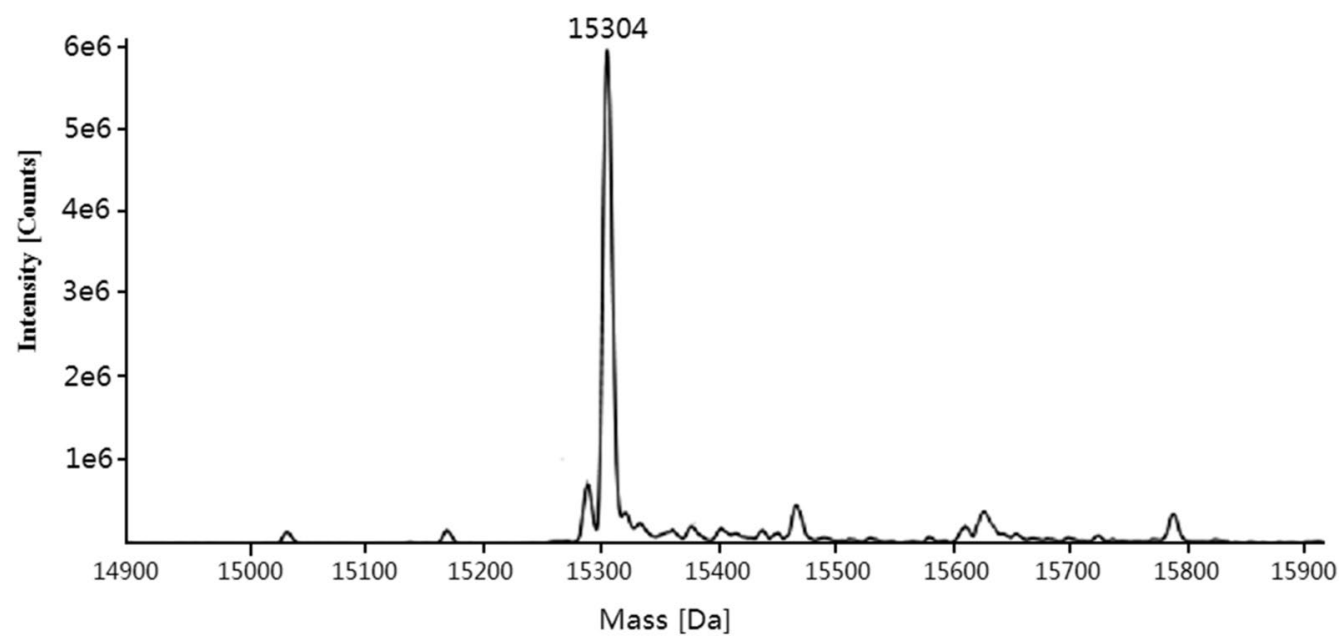

Fig. $4 \mathrm{MS}$ analysis of $\mathrm{rHtA}$. Purified $\mathrm{rHtA}$ was measured By MS. The MW of $\mathrm{rHtA}$ was calculated at $\sim 15.3 \mathrm{kDa}$

Table 2 Peptide segments were observed by nanoLC-MS/MS

\begin{tabular}{|c|c|c|c|c|c|}
\hline No. & Sequence & No. & Sequence & No. & Sequence \\
\hline 1 & APIVTCR & 13 & SGDPHRYFAGDHIR & 25 & GGPTPIR \\
\hline 2 & APIVTCRPK & 14 & YFAGDHIR & 26 & GGPTPIRVYYANSR \\
\hline 3 & APIVTCRPKLDGR & 15 & YFAGDHIRWGVNNCDK & 27 & WYANSR \\
\hline 4 & LDGREKPFK & 16 & WGVNNCDK & 28 & GAVQYCGVMTHSK \\
\hline 5 & EKPFKVDVATAQAQAR & 17 & WGVNNCDKADAILWEYPIYWVGK & 29 & GAVQYCGVMTHSKVDK \\
\hline 6 & PFKVDVATAQAQAR & 18 & ADAILWEYPIYWVGK & 30 & GAVQYCGVMTHSKVDKNNQGK \\
\hline 7 & VDVATAQAQAR & 19 & ADAILWEYPIYWVGKNAEWAK & 31 & VDKNNQGK \\
\hline 8 & VDVATAQAQARK & 20 & NAEWAKDVK & 32 & VDKNNQGKEFFEK \\
\hline 9 & KAGLTTGK & 21 & NAEWAKDVKTSQQK & 33 & NNQGKEFFEK \\
\hline 10 & KAGLTTGKSGDPHR & 22 & DVKTSQQK & 34 & EFFEKCDHHHHHH \\
\hline 11 & AGLTTGK & 23 & DVKTSQQKGGPTPIR & & \\
\hline 12 & AGLTTGKSGDPHR & 24 & TSQQKGGPTPIR & & \\
\hline
\end{tabular}

that purified rHtA harboured a native $\mathrm{N}$-terminus and a fused $6 \times$ His tag at the C-terminus.

\section{Analysis of the thermal- and protease-stability of the purified $\mathrm{rHtA}$}

The results of SDS-PAGE and thermal- and proteasestability studies are shown in Fig. 5 . The protein became insoluble after thermal-denaturation treatment, with the denatured proteins precipitating during high-speed centrifugation. After 30 -min incubation at $98{ }^{\circ} \mathrm{C}, 65 \%$ of rHtA remained soluble and nearly $20 \%$ of $\mathrm{rHtA}$ remained soluble after $4 \mathrm{~h}$ of heat incubation (Fig. 5a). These results showed that purified $\mathrm{rHtA}$ showed high thermal tolerance.
Protease-stability studies showed that $28 \%$ of $\mathrm{rHtA}$ underwent digestion after a 10-min incubation with trypsin, and $53 \%$ of rHtA was digested after $30 \mathrm{~min}$. Prolonged digestion of $2 \mathrm{~h}$ resulted in $>20 \%$ of purified $\mathrm{rHtA}$ remaining intact (Fig. 5b). Protease treatment using proteinase $\mathrm{K}$ showed that rHtA exhibited excellent stability, with only $10 \%$ of rHtA digested after $10 \mathrm{~min}$ and $30 \%$ digested after a 2 -h digestion (Fig. $5 \mathrm{c}$ ). These results indicate that rHtA is more stable in the presence of proteinase $\mathrm{K}$ and exhibits overall excellent stability to protease treatment.

\section{The purified rHtA inhibits the growth of sf9 insect cells}

Effect of purified rHtA on cell proliferation of sf9 insect cells was analyzed by MTT assay. Without adding rHtA to the media, the absorbance value of MTT at $570 \mathrm{~nm}$ 


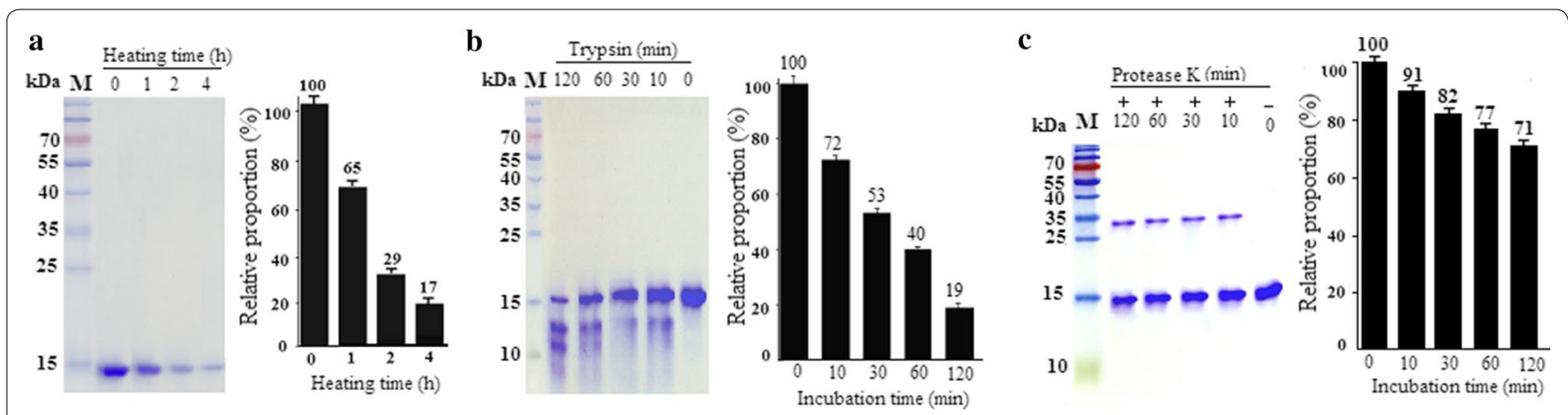

Fig. 5 Thermal- and protease-stability analyses. a Thermal-stability analysis. b Proteinase K-stability analysis. c Trypsin-stability analysis. Purified rHtA was incubated at the indicated times

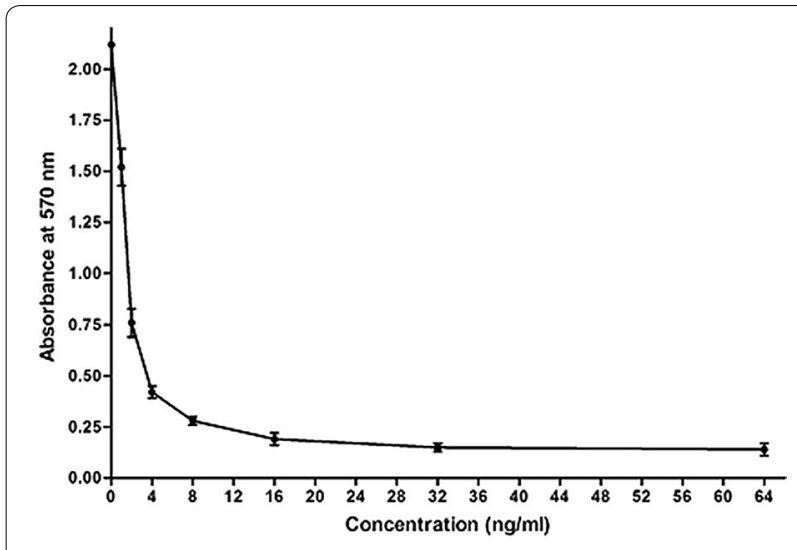

Fig. 6 MTT assay of Sf9 cell proliferation. The growth of Sf9 cells was analysed at the given concentrations of $\mathrm{rHtA}$ in 96-well plates. The $X$-axis shows the absorbance at $570 \mathrm{~nm}$, and the $Y$-axis shows the final $\mathrm{rHt}$ A concentration added to the culture medium. Data represent the mean \pm standard deviation of triplicate experiments

was 2.3. After addition of $1 \mathrm{ng} / \mathrm{ml} \mathrm{rHtA}$ to insect-cell medium, the absorbance value of MTT at $570 \mathrm{~nm}$ was about 1.6 , which means $70 \%$ of the cells remained viable as compared with those treated with PBS (Fig. 6). When the final rHtA concentration was increased to $2 \mathrm{ng} / \mathrm{ml}$, about $35 \%$ of the cells remained viable relative to controls. Further increases in rHtA concentration $(4-16 \mathrm{ng} / \mathrm{ml})$ in the media resulted in continued decreases in cell viability. When the rHtA concentration was over $32 \mathrm{ng} / \mathrm{ml}$, few viable cells remained. These results confirmed the ability of rHtA to inhibit the growth of sf9 insect cells, demonstrating that rHtA purified from $P$. pastoris has cytotoxic effects on sf9 cells.

\section{The purified $\mathrm{rHtA}$ is toxic to G. mellonella}

Galleria mellonella injected with $\mathrm{rHtA}$ showed classic symptoms of ribotoxin poisoning, including brownish coloration progressing to black upon death, whereas no discoloration was observed in worms injected with PBS (Fig. 7a). Insect-toxicity results are shown in Table 3. Upon increasing the dose to $1 \mu \mathrm{g}, 6$ larvae (20\%) died after 3 days, and the dead larvae were black. Different injection times showed obvious differences in associated mortality, and the dose of $4 \mu \mathrm{g}$ resulted in $100 \%$ mortality after 4 days (Fig. 7b). Discoloration at this dose began at $12 \mathrm{~h}$ and darker shading was observed after $24 \mathrm{~h}$. And, death was observed after $36 \mathrm{~h}$. The dose of $8 \mu \mathrm{g}$ resulted in $100 \%$ mortality after 3 days. Although $6.7 \%$ of control G. mellonella larvae died after 4 days, their coloration had not changed, suggesting no symptoms of ribotoxin poisoning. These results indicate that rHtA is toxic to $G$. mellonella.

\section{Discussion}

More than 20 years since the discovery of HtA, there has not been any report on its application in biological control $[14,15]$. The most likely reason is that an efficient heterologous expression system has not yet been established, leading to the uncertainty of its insecticidal activity against agricultural pests. In this study, a large amount of rHtA was prepared from $P$. pastoris by high density fermentation. Compared with the shaking flasks fermentation in BMMY medium, the fed-batch high cell density fermentation of $P$. pastoris in basic salt media produced significantly higher rHtA. DO is critical to expression efficiency in the $P$. pastoris system [20, 21]. Heat transfer is another important limiting factor in high cell density $P$. pastoris cultivations [22]. The NCBIO bioreactor system is able to maintain constant temperature and $30 \% \mathrm{DO}$ by feeding and DO-series connection. As a result, as high as about $440 \mathrm{~g} / \mathrm{l}$ wet weight of $P$. pastoris cells were produced by the end of culture in the NCBIO bioreactor. In previous reports, several grams per litre of recombinant proteins have been produced during fed-batch production processes $[23,24]$. In this study, though the protein was not obtained at gram per litre level, it is enough to 


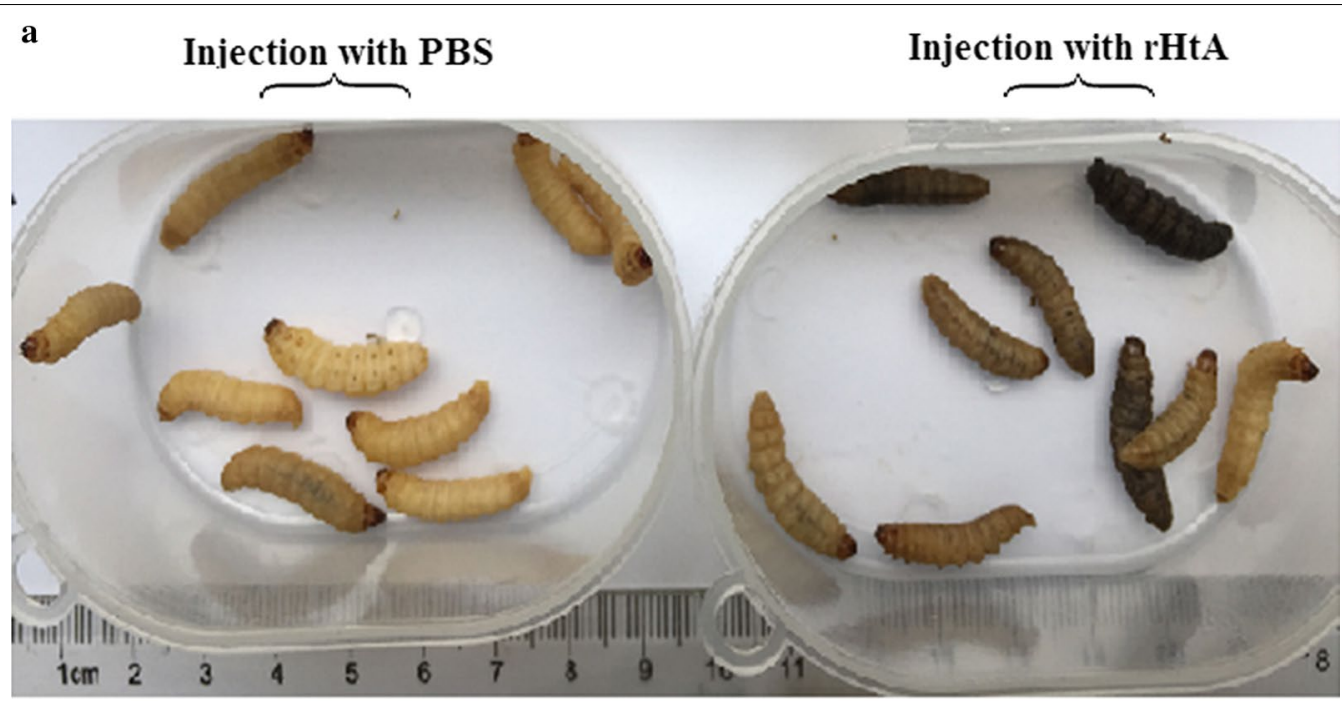

b

Post-injection with rHtA (h)

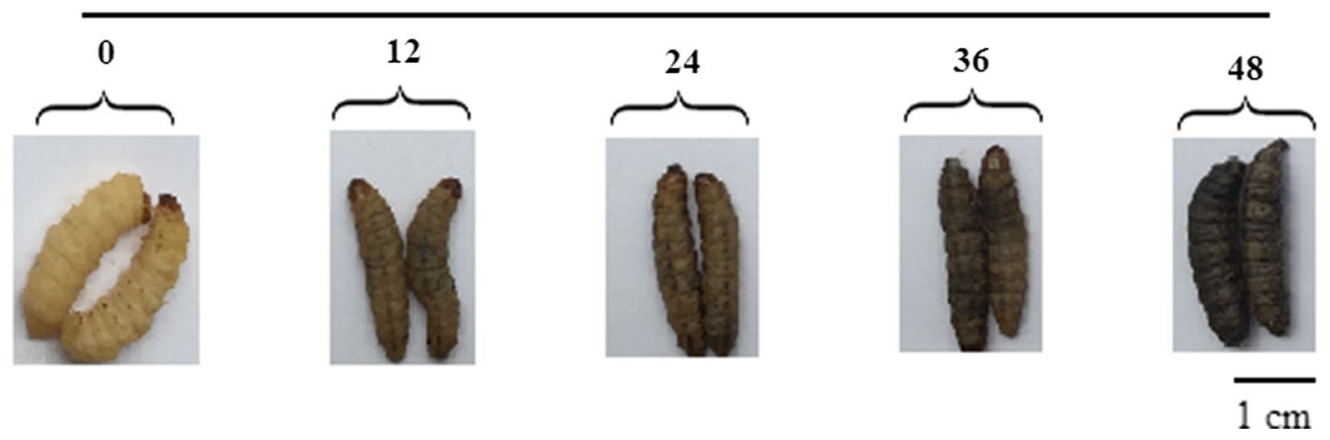

Fig. 7 Injection-toxicity assays using rHtA. a Galleria mellonella larvae injected with $4 \mu \mathrm{g}$ of purified $\mathrm{rHtA}$ or PBS as a control. b Time course of G. mellonella larvae injected with $4 \mu \mathrm{g}$ of purified $\mathrm{rHtA}$ per larvae

Table 3 Injection toxicity assays of rHtA

\begin{tabular}{|c|c|c|c|c|c|}
\hline \multirow[t]{2}{*}{ Samples ( $\mu \mathrm{g} /$ larvae) } & \multicolumn{5}{|l|}{ Mortality (\%) } \\
\hline & 1 day post injection & 2 days post injection & 3 days post injection & 4 days post injection & $\begin{array}{l}5 \text { days } \\
\text { post injection }\end{array}$ \\
\hline PBS & 0 & 0 & 0 & 6.7 & 6.7 \\
\hline 1 & 0 & 9.9 & 20.0 & 26.7 & 40.0 \\
\hline 2 & 13.3 & 33.3 & 46.7 & 66.7 & 93.3 \\
\hline 4 & 36.7 & 83.3 & 93.3 & 100 & 100 \\
\hline 8 & 53.3 & 90 & 100 & 100 & 100 \\
\hline
\end{tabular}

produce rHtA for the insecticidal activity analysis, especially for its oral insecticidal activity against agricultural pests. And, the safety of HtA, which cannot be performed without a large amount of purified rHtA protein, may be comprehensively tested. Additionally, the establishment of rHtA efficient preparation system will also facilitate us to carry out the safety tests in mammalians. 
Gene-copy number is an important factor affecting the expression of recombinant proteins, and the most common strategy for selecting $P$. pastoris transformants is to screen multi-copy integrations of an expression cassette [25-27]. In this study, transformants from YPD plates treated with $1 \mathrm{mg} / \mathrm{ml}$ zeocin were selected. Almost all the selected transformants showed high levels of rHtA secretion, suggesting that large number of expression cassettes are incorporated into $P$. pastoris. Colonies obtained using $\mathrm{LiCl}$ were limited, with only 20 colonies selected from $1 \mathrm{mg} / \mathrm{ml}$ zeocin YPD plates, and no transformants obtained from plates with higher zeocin concentration (1.5 $\mathrm{mg} / \mathrm{ml}$ zeocin).

All published protocols related to rHtA purification consist of at least four different purification steps to obtain $>95 \%$ purity [15]. In the present study, $\sim 7 \mathrm{mg}$ of highly pure rHtA was obtained using a two-step purification procedure from $300 \mathrm{ml}$ of crude fermentation supernatant. The concentration of purified rHtA was $>20$-fold higher that that previously reported in E. coli [12]. This purification procedure resulted in higher levels of purified rHtA with fewer contaminated proteins. Although nickel-affinity chromatography eliminated most of the contaminated proteins, additional round of chromatographic purification were necessary. Additional purification steps involving dialysis using a buffer with a higher $\mathrm{pH}$ eliminated the binding of contaminated proteins to the Sepharose column. Here, the purified rHtA variant contained a $6 \times \mathrm{His}$ tag at the $\mathrm{C}$-terminus. In previous studies, rhPDGF-AA with a native amino acid sequence was purified from $P$. pastoris by one-step CM ionexchange chromatography at its theoretical pI of 8.6 [28]. The theoretical pI of rHtA is 9.3, which is higher than that of rhPDGF-AA, indicating that native rHtA might be capable of purification using a single step of ion-exchange chromatography directly from the $P$. pastoris fermentation supernatant. Glycosylation is a common posttranslational protein modification in $P$. pastoris, which is frequently found on secreted proteins $[18,19]$. Here, determination of rHtA MW indicated that the purified variant was not glycosylated. Therefore, these results suggest that $P$. pastoris is suitable for the preparation of large amounts of unmodified and highly active rHtA.

The thermo stability of insecticidal protein is an important factor affecting its application in biological control. In this study, the thermal stability of rHtA was assayed, revealing that almost all $\mathrm{rHtA}$ remained soluble following incubation at $56{ }^{\circ} \mathrm{C}$ for $24 \mathrm{~h}$ (data not shown). After incubation at $98{ }^{\circ} \mathrm{C}$ for $1 \mathrm{~h}, 65 \% \mathrm{rHtA}$ remained intact, which is consistent with a previous report [14]. The soluble rHtA after heat treatment remained bioactivity by injecting G. mellonella larvae (data not shown). High thermal stability might facilitate the use of rHtA as an insecticide.
The stability of rHtA to protease also affects its insecticidal activity. In this study, rHtA was not sensitive to protein $\mathrm{K}$. However, protease-stability analysis showed two degradation bands following trypsin digestion, with each band having an MW between 10 and $15 \mathrm{kDa}$. In this study, the rHtA solution treated by proteases also remained bioactivity by injecting G. mellonella larvae (data not shown). A previous report indicated that trypsin digestion at room temperature overnight did not affect the insecticidal activity of native HtA, indicating that the protein fragments digested by trypsin may be still biologically active [14]. The three-dimensional structure of HtA also suggests that maintenance of ribosomaltoxin activity does not require the full-length sequence [12]. Therefore, further study of the trypsin-digested fragments might help determine the structural components necessary for HtA activity.

In vivo injection of native HtA is highly toxic to insects, such as G. mellonella larvae [29]. In the present study, injection of $1 \mu \mathrm{g} \mathrm{rHtA}$ per larvae, equivalent to $4 \mu \mathrm{g} / \mathrm{g}$ body weight, resulted in $40 \%$ mortality after 5 days, which is similar to results using native HtA (mortality after 8.8 days) [14]. Additionally, G. mellonella larval activity was obviously weaker following injection with rHtA relative to controls (Additional file 1). These results indicate that $\mathrm{rHtA}$ expressed in P. pastoris shows comparable activity as that of native HtA. HtA exhibits strong activity following injection and obvious oral toxicity, possibly also exhibiting contact activity, which may represent an insecticidal pathway rare among other insecticidal proteins [14]. High levels of insecticidal activity and multiple insecticidal pathways expand the potential applications of such proteins in biological control. Future studies on the oral and/or contact toxicity of HtA are warranted.

Some insecticidal proteins, such as insect neurotoxins, exhibit strong haemocoel-injection activity and can be used to enhance the insecticidal activity of recombinant proteins produced by microorganisms, such as insect pathogenic viruses and entomopathogenic fungi [30-32]. Some insecticidal proteins result in oral toxicity and can be used to obtain genetic engineered plants for insect control $[33,34]$. HtA is cytotoxic to insect cells and mammalian cells, suggesting it as an indiscriminate insecticidal protein, which might limit its potential use as an insecticidal agent. Fortunately, the potential toxicity of HtA against vertebrates can be overcome by the design of new variants, such as those involving Trp mutations [35]. Protein fusions can also enhance insecticidal activity or alter the insecticidal pathway [36, 37]. Therefore, HtA might be a candidate for genetic engineering and may fuse with other insecticidal proteins, such as snowdrop lectin, specific insect neurotoxins (from spider, scorpion or other poisonous animals) or Cry toxin from 
Bacillus thuringiensis, to enhance its insecticidal activity or change its insecticidal pathway.

\section{Conclusions}

In conclusion, for the first time, this study reported high levels of rHtA expression by high-cell-density fedbatch fermentation in P. pastoris. Highly pure rHtA was obtained using a two-step purification method. The steps were simpler and more efficient than previously reported purification protocols. Protein assays showed that $\mathrm{rHtA}$ was a non-glycosylated monomeric protein with a native $\mathrm{N}$-terminal region, and had excellent thermal and protease stability and high levels of insecticidal activities. The preparation of large amounts of highly active rHtA will facilitate insecticidal-activity studies on agricultural pests and contribute to the development of new bioinsecticide.

\section{Methods \\ Construction of expression plasmid and transformation of $P$. pastoris}

$H t A$ harbouring a $6 \times$ His tag at the $\mathrm{C}$-terminus was synthesized according to its amino acid sequence and $P$. pastoris codon bias (http://www.kazusa.or.jp/codon/cgi-bin/ showcodon.cgi?species=4922). To obtain native N-terminal rHtA, a Kex2 signal-cleavage site (aaa aga) was fused to the upstream region of the synthetic cDNA. The sequence of the synthetic $H t A$ gene was as follows: CTC GAG aaa aga GCCCCAATCGTCACCTGCAGACCA AAGTTGGACGGTAGAGAGAAGCCATTCAAGGTC GACGTCGCCACTGCCCAGGCTCAAGCCAGAAAG GCCGGTTTGACCACCGGTAAGTCCGGTGACCCA CACAGATACTTCGCCGGAGACCACATCAGATGG GGTGTCAACAACTGCGACAAGGCCGACGCCATC TTGTGGGAGTACCCAATCTACTGGGTCGGTAAG AACGCCGAGTGGGCCAAGGACGTCAAGACCTCC CAGCAGAAGGGTGGACCAACCCCAATCAGAGTT GTCTACGCCAACTCCAGAGGTGCCGTCCAATAC TGCGGAGTCATGACCCACTCCAAGGTCGACAAG AACAACCAGGGAAAGGAGTTCTTCGAGAAGTGC GACCACCACCACCACCACCAC TAA TCTAGA. The synthesized DNA fragments of $H t A$ were digested with $X h o \mathrm{I}$ and $X b a \mathrm{I}$ and inserted into the pPICZ $\alpha \mathrm{A}$ vector (Invitrogen, Carlsbad, CA, USA). The expression vector was linearized by digestion with SacI and transformed into P. pastoris $\mathrm{X} 33$ using $\mathrm{LiCl}$ according to manufacturer instructions (Invitrogen, Carlsbad, CA, USA). $P$. pastoris transformants were grown on yeast extract-peptone-dextrose (YPD) plates containing $100 \mu \mathrm{g} / \mathrm{ml}$ zeocin. Transformants with multiple expression cassettes were screened using increasing concentrations of zeocin from 200, 400, 800, and $1000 \mu \mathrm{g} / \mathrm{ml}$. Positive transformants were verified by PCR.

\section{Screening of transformants with high level expression of rHtA}

After incubation at $28{ }^{\circ} \mathrm{C}$ for 3 days on the YPD plates containing $1000 \mu \mathrm{g} / \mathrm{ml}$ zeocin, twenty positive transformants verified by PCR were grown respectively in $10 \mathrm{ml}$ buffered-glycerol complex medium (BMGY) at $28^{\circ} \mathrm{C}$ with shaking at $250 \mathrm{rpm}$ for $24 \mathrm{~h}$. Cells were harvested by centrifugation at $1500 \mathrm{~g}$ for $10 \mathrm{~min}$ at $28^{\circ} \mathrm{C}$ and resuspended in $2 \mathrm{ml}$ buffered-methanol complex medium (BMMY). Twenty microliters of $100 \%$ methanol was added to each tube every $24 \mathrm{~h}$. After induction at $28{ }^{\circ} \mathrm{C}$ with shaking at $250 \mathrm{rpm}$ for $72 \mathrm{~h}$, cell cultures were collected by centrifugation at $12,000 \mathrm{~g}$ for $10 \mathrm{~min}$ at $4{ }^{\circ} \mathrm{C}$. Supernatants $(0.9 \mathrm{ml})$ were mixed with $0.1 \mathrm{ml} 100 \%$ trichloroacetic acid (TCA) and incubated at $-20{ }^{\circ} \mathrm{C}$ for $4 \mathrm{~h}$. After centrifugation at $12,000 \mathrm{~g}$ for $30 \mathrm{~min}$ at $4{ }^{\circ} \mathrm{C}$, precipitates were washed with $1 \mathrm{ml}$ acetone by centrifugation at $12,000 \mathrm{~g}$ for $10 \mathrm{~min}$ at $4{ }^{\circ} \mathrm{C}$, followed by resuspension in $50 \mu \mathrm{l}$ of $1 \times$ reduced loading buffer containing $8 \mathrm{M}$ urea. Samples $(10 \mu \mathrm{l})$ were analysed by SDS-PAGE.

\section{Time course of $\mathrm{rHtA}$ expression in shake flasks}

The colony with the highest rHtA expression was cultured in $400 \mathrm{ml}$ BMGY with shaking at $28{ }^{\circ} \mathrm{C}$ to an optical density at $600 \mathrm{~nm}$ of $\sim 15$. Cells were harvested by centrifugation at $1500 \mathrm{~g}$ for $10 \mathrm{~min}$ at $28{ }^{\circ} \mathrm{C}$, followed by resuspension in $60 \mathrm{ml}$ BMMY and growth for 4 days at $28{ }^{\circ} \mathrm{C}$ with shaking at $250 \mathrm{rpm}$. Each day, $600 \mu \mathrm{l}$ of $100 \%$ methanol was added to the medium. Before adding methanol, $2 \mathrm{ml}$ culture samples were collected by centrifugation at $15,000 \mathrm{~g}$ for $10 \mathrm{~min}$ at $4{ }^{\circ} \mathrm{C}$, and $0.9 \mathrm{ml}$ samples of the supernatants were precipitated with TCA according to methods described in the previous section. The pellets were resuspended in $40 \mu \mathrm{l}$ of $1 \times$ SDS loading buffer containing $8 \mathrm{M}$ urea and subjected to SDS-PAGE analysis. The amount of secreted rHtA was determined by scanning the gel using Quantity One software (Bio-Rad, Hercules, CA, USA). The time course associated with rHtA expression was confirmed by western blot analysis using a rabbit anti-His $\times 6$ IgG antibody (CST, Guangzhou, China).

\section{Fed-batch fermentation}

One colony with high $\mathrm{rHtA}$ expression was used to inoculate into $5 \mathrm{ml} \mathrm{YPD}$ media, grown for $20 \mathrm{~h}$ at $28^{\circ} \mathrm{C}$, followed by scaling up with $300 \mathrm{ml}$ fed-batch basalsalts media containing $2 \%(\mathrm{w} / \mathrm{v})$ glycerol and shaking at $250 \mathrm{rpm}$ and $28^{\circ} \mathrm{C}$ until reaching an optical density at $600 \mathrm{~nm}$ of 10. Scale-up expression was performed in a 5-1 bioreactor (NCBIO, China, Shanghai) using 2.7-l basalsalts medium. The composition and preparation of fedbatch basal-salts medium and trace metal solution (TMS) were referred to previous reports [38]. Feeding mixture 
contains: $100 \mathrm{ml}$ of $70 \%$ glycerol solution plus $1.2 \mathrm{ml}$ TMS. Induction mixture contains: $100 \mathrm{ml}$ of methanol plus $1.2 \mathrm{ml}$ TMS. Compressed air was maintained at $6 \mathrm{l} /$ min, dissolved oxygen (DO) was maintained at $>40 \%$ saturation by stirring at between 200 and $1000 \mathrm{rpm}$, and temperature was maintained at $28{ }^{\circ} \mathrm{C}$. Fermentation was initiated by adding $300 \mathrm{ml}$ of fed-batch basal-salts seed culture into 2.7-l basal-salts medium, with the medium $\mathrm{pH}$ maintained at 6.0 by adding $30 \%$ ammonium hydroxide. To maintain glycerol concentration in the glycerol fed-batch phase, the feeding mixture was added automatically according to DO $>40 \%$ saturation by automatic series regulation. After all feed solution was consumed, the induction solution was added to initiate an 84-h induction, and the medium $\mathrm{pH}$ was maintained at 6.0 by adding $30 \%$ ammonium hydroxide. The methanolfeeding method used for induction was as follows: the feeding rate of methanol was controlled at $3.6 \mathrm{ml} / \mathrm{h}$ for $12 \mathrm{~h}, 5.4 \mathrm{ml} / \mathrm{h}$ for $24 \mathrm{~h}, 7.2 \mathrm{ml} / \mathrm{h}$ for $36 \mathrm{~h}$, and $5.4 \mathrm{ml} / \mathrm{h}$ for $12 \mathrm{~h}$. Cell-culture samples $(10 \mathrm{ml})$ were collected at 0,12 , $24,36,48,60,72$, and $84 \mathrm{~h}$ after methanol induction. For each time-point, $0.9 \mathrm{ml}$ of supernatant was precipitated with TCA as described, precipitates were resuspended in $100 \mu \mathrm{l}$ of $1 \times$ SDS loading buffer, and $10 \mu \mathrm{l}$ samples were subjected to SDS-PAGE analysis. The amount of secreted rHtA was determined by gel scanning as described. The wet weight of cultured cells was obtained by centrifugation. Protein concentration in the supernatant was determined by Bradford assay. The expressed rHtA was verified by western blot using a rabbit anti-His $\times 6$ IgG antibody.

\section{Purification of rHtA}

After an 84-h induction with methanol, $300 \mathrm{ml}$ of the supernatant from the bioreactor was centrifuged at $15,000 \mathrm{~g}$ for $60 \mathrm{~min}$ at $4{ }^{\circ} \mathrm{C}$, followed by adjustment to $\mathrm{pH} 8.0$ with $2 \mathrm{M}$ sodium hydroxide. Using a peristaltic pump at a flow rate of $1.5 \mathrm{ml} / \mathrm{min}$, the supernatant was loaded onto a $50-\mathrm{ml}$ column containing $4 \mathrm{ml} \mathrm{Ni}^{+}$-NTA resin (Qiagen, Guangzhou, China) that was pre-equilibrated with buffer A (20 mM PBS, pH 8.0, and $200 \mathrm{mM}$ $\mathrm{NaCl})$. The column was then washed with $200 \mathrm{ml}$ buffer B (20 mM PBS, pH 8.0, $200 \mathrm{mM} \mathrm{NaCl}$, and $30 \mathrm{mM}$ imidazole) to remove unbound proteins. rHtA was eluted using an imidazole gradient ranging from 50 to $500 \mathrm{mM}$ imidazole in $20 \mathrm{ml}$ buffer B. The collected protein samples were subjected to SDS-PAGE analysis and stained with Coomassie Brilliant Blue R250.

All collected protein samples were concentrated using $15-\mathrm{ml}$ filters with a molecular weight cut off of $3 \mathrm{kDa}$ (Millipore, Billerica, MA, USA), centrifuged at $4000 g$ for $60 \mathrm{~min}$ at $4{ }^{\circ} \mathrm{C}$, subjected to SDS-PAGE analysis and stained with Coomassie Brilliant Blue R250. The concentrated proteins were dialyzed against $500 \mathrm{ml}$ buffer $\mathrm{C}(40 \mathrm{mM}$ PBS, $\mathrm{pH} 8.5$, and $50 \mathrm{mM} \mathrm{NaCl})$ at $4{ }^{\circ} \mathrm{C}$ three times. After centrifugation at $15,000 \mathrm{~g}$ for $60 \mathrm{~min}$ at $4{ }^{\circ} \mathrm{C}$, the dialyzed supernatants were loaded onto a $1-\mathrm{ml}$ CM Sepharose FF column (GE Health care, Guangzhou, China) that was pre-equilibrated using buffer $\mathrm{C}$. The column was washed with $400 \mathrm{ml}$ buffer D (40 mM PBS, pH 8.5 , and $100 \mathrm{mM} \mathrm{NaCl}$ ) to remove unbound proteins. rHtA was eluted with buffer E (40 mM PBS, pH 7.4, and $500 \mathrm{mM} \mathrm{NaCl}$ ). After dialysis against $40 \mathrm{mM}$ PBS, $\mathrm{pH}$ 7.4 , and $50 \mathrm{mM} \mathrm{NaCl}$, the collected solution was concentrated and subjected to SDS-PAGE analysis in the presence or absence of DTT and staining with Coomassie Brilliant Blue R250.

\section{Determination of the molecular weight (MW) and amino acid sequence of $\mathrm{rHtA}$}

The MW of rHtA was determined by high-performance liquid chromatography using $30 \mu \mathrm{g}$ of purified rHtA, a C4 chromatographic column (Agilent Technologies, Santa Clara, CA, USA), and a high resolution 6520 quadrupole time of flight mass spectrometry (Q-TOF-MS) proteomics analyser (Agilent Technologies) with a scan range from 500 to $4000 \mathrm{~m} / \mathrm{z}$. The accurate MW of rHtA was calculated by deconvolution of the raw MS data.

The amino acid sequence of rHtA was determined by mass spectrometry. The purified rHtA was reduced for 40 min with $5 \mathrm{mM}$ DTT at room temperature followed by alkylation for $40 \mathrm{~min}$ with $15 \mathrm{mM}$ iodoacetamide in a dark room. The alkylated protein samples were digested overnight at $37{ }^{\circ} \mathrm{C}$ with trypsin (Promega, Shanghai, China) at a 1:50 enzyme-to-substrate ratio. Following digestion, the peptide mixtures were acidified with trifluoroacetic acid to $1 \%$ and desalted. The desalted peptide samples were dried in a vacuum concentrator, dissolved in $10 \mu \mathrm{l}$ of $0.1 \%$ formic acid in water, and the purified peptide samples were subjected to nano-liquid chromatography tandem MS (nano-LC-MS/MS) analysis. Raw MS data were analysed and searched against proteinsequence databases using Proteome Discoverer (Thermo Fisher Scientific, Waltham, MA, USA).

\section{Thermal- and protease-stability analyses}

Thermal-stability analysis was determined by incubation of $100 \mu \mathrm{l}$ of $1 \mathrm{mg} / \mathrm{ml}$ pure rHtA in PBS for $0,0.5,1,2$, and $4 \mathrm{~h}$ at $98{ }^{\circ} \mathrm{C}$. After centrifugation at $17,000 \mathrm{~g}$ for $30 \mathrm{~min}$ at $4{ }^{\circ} \mathrm{C}, 40 \mu \mathrm{l}$ of the supernatant was mixed with $10 \mu \mathrm{l}$ of $5 \times$ SDS loading buffer, and 10- $\mu \mathrm{l}$ samples were subjected to SDS-PAGE analysis. Protease stability was determined by incubating $1 \mathrm{mg} / \mathrm{ml}$ pure rHtA in PBS for $0,15,30,60$, and $120 \mathrm{~min}$ at $30{ }^{\circ} \mathrm{C}$ with proteinase $\mathrm{K}$ or trypsin at a final concentration of $500 \mu \mathrm{g} / \mathrm{ml}$. At the end of the incubation period, $3 \mathrm{mM}$ phenylmethanesulfonyl fluoride 
was added to terminate the reaction. Finally, $20 \mu \mathrm{l}$ of the digestion products were mixed with $5 \mu \mathrm{l}$ of $5 \times$ SDS loading buffer, and 10- $\mu$ l samples were subjected to SDSPAGE analysis.

\section{MTT assay}

Sf9 cells (Procell, Wuhan, China) were cultured in insectcell medium (Sino Biological, Beijing, China) in a cellculture flask at $27^{\circ} \mathrm{C}$. When the cell confluence reached 80-90\%, cells were resuspended in insect-cell medium, and the cell density was adjusted to $2 \times 10^{5}$ cells $/ \mathrm{ml}$. Sf9 cells $(100 \mu \mathrm{l})$ were added to each well of a 96-well plate (Corning, Guangzhou, China) and incubated at $27{ }^{\circ} \mathrm{C}$ for $24 \mathrm{~h}$. Different final concentrations of rHtA $(0,1,2$, $4,8,16,32$, and $64 \mathrm{ng} / \mathrm{ml}$ ) were added and incubated at $27{ }^{\circ} \mathrm{C}$ for $48 \mathrm{~h}$, and cell proliferation was determined by 3-(4,5-dimethylthiazol-2-yl)-2,5-diphenyltetrazolium bromide (MTT) assay. Briefly, $10 \mu \mathrm{l}$ MTT solution $(5 \mathrm{mg} /$ $\mathrm{ml}$ MTT in PBS) was added to each well of the 96-well plate, followed by incubation at $27^{\circ} \mathrm{C}$ for $4 \mathrm{~h}$, after which media supernatants were discarded carefully. Dimethyl sulfoxide $(100 \mu \mathrm{l})$ was then added to each well to dissolve the formazan for $10 \mathrm{~min}$ at $37^{\circ} \mathrm{C}$. Absorbance was measured on an ELISA plate reader (BioTek ELX800, BioTek Instruments Inc., Vermont, USA) at a wavelength of $570 \mathrm{~nm}$.

\section{Insect bioassays}

To evaluate the injection bioactivity of purified rHtA, the final instar larval-stage G. mellonella were used (weight: $0.22 \pm 0.04 \mathrm{~g}$ ). G. mellonella were incubated on ice prior to use. Recombinant HtA was injected at the third and fourth abdominal segments using 10- $\mu$ l sharp Hamilton syringes (Sigma-Aldrich, St. Louis, MO, USA). Each larva was injected with $1,2,4$ or $8 \mu \mathrm{g}$ of purified rHtA (1 mg/ $\mathrm{ml}$ in PBS) or $10 \mu \mathrm{lBS}$ as control. Post-injection toxicity was monitored with a lethality test every $24 \mathrm{~h}$, and dead larvae were immediately removed. For each treatment, three replicates of 30 larvae were tested.

\section{Additional file}

Additional file 1. Video after five days of injection $1 \mu \mathrm{g}$ of $\mathrm{rHtA}$ per larva or PBS.

\footnotetext{
Abbreviations

HRP: horseradish peroxidase; SDS-PAGE: sodium dodecyl sulfate-polyacrylamide gel electrophoresis; NTA: $\mathrm{Ni}^{2+}$-nitriloacetic acid; MWCO: molecular weight cut off; TMS: trace metal solution; PCR: polymerase chain reaction; MW: molecular weight; DO: dissolved oxygen; PBS: phosphate buffered solution; PMSF: phenylmethanesulfonyl fluoride; DTT: DL-Dithiothreitol; MTT: 3-(4, 5-dimethylthiazol-2-yl)-2, 5-diphenyltetrazolium bromide.
}

\section{Authors' contributions}

$\mathrm{HL}$ carried out the experiments. $\mathrm{HL}$ and $Y X$ participated in the design of the study, and supervised the research work. HL and $Y X$ drafted the original manuscript. Both authors read and approved the final manuscript.

\section{Author details \\ ${ }^{1}$ Postdoctoral Mobile Station of Biology, Genetic Engineering Research Center, College of Life Sciences, Chongqing University, Chongqing 400030, China. ${ }^{2}$ College of Biological and Food Engineering, Huaihua University, Huaihua 418008, China. ${ }^{3}$ Genetic Engineering Research Center, College of Life Sciences, Chongqing University, No. 55 South Road of University Town, Shap- ingba District, Chongqing 401331, China.}

\section{Acknowledgements \\ Not applicable.}

\section{Competing interests}

The authors declare that they have no competing interests.

\section{Availability of data and materials}

All datasets on which the conclusions of the manuscript rely are presented in the main paper.

\section{Consent for publication}

All the authors agree to submit the manuscript to this journal.

\section{Ethics approval and consent to participate}

Not applicable.

\section{Funding}

This work was supported by Funds from Project funded by China Postdoctoral Science Foundation (2016M590867), Project funded of Chongqing Postdoctoral Science Foundation (Xm2016075) and Scientific Research Fund of Hunan Provincial Education Department (15A147).

\section{Publisher's Note}

Springer Nature remains neutral with regard to jurisdictional claims in published maps and institutional affiliations.

Received: 10 February 2018 Accepted: 5 September 2018

Published online: 14 September 2018

\section{References}

1. Jeschke P. Propesticides and their use as agrochemicals. Pest Manag Sci. 2016;72:210-25.

2. Feng $Y$, Zhang A. A floral fragrance, methyl benzoate, is an efficient green pesticide. Sci Rep. 2017;7:42168

3. Olombrada M, Lázaro-Gorines R, López-Rodríguez JC, Martínez-Del-Pozo Á, Oñaderra M, Maestro-López M, Lacadena J, Gavilanes JG, García-Ortega L. Fungal ribotoxins: a review of potential biotechnological applications. Toxins (Basel). 2017;71:1-21.

4. Michiels K, Van Damme EJ, Smagghe G. Plant-insect interactions: what can we learn from plant lectins? Arch Insect Biochem Physiol. 2010;73:193-212.

5. Kawachi T, Miyashita M, Nakagawa Y, Miyagawa H. Isolation and characterization of an anti-insect $\beta$-toxin from the venom of the scorpion Isometrus maculatus. Biosci Biotechnol Biochem. 2013;77:205-7.

6. Barcoto MO, Pedrosa F, Bueno OC, Rodrigues A. Pathogenic nature of Syncephalastrum in Atta sexdens rubropilosa fungus gardens. Pest Manag Sci. 2017;73:999-1009.

7. Bideshi DK, Park HW, Hice RH, Wirth MC, Federici BA. Highly effective broad spectrum chimeric larvicide that targets vector mosquitoes using a lipophilic protein. Sci Rep. 2017;7:11282.

8. Pérez MP, Sauka DH, Onco MI, Berretta MF, Benintende GB. Selection of Bacillus thuringiensis strains toxic to cotton boll weevil (Anthonomus grandis, Coleoptera: Curculionidae) larvae. Rev Argent Microbiol. 2017;49:264-72. 
9. Lovett B, St Leger RJ. Genetically engineering better fungal biopesticides. Pest Manag Sci. 2018;74:781-9.

10. Olombrada M, Medina P, Budia F, Gavilanes JG, Martínez-Del-Pozo Á, García-Ortega L. Characterization of a new toxin from the entomopathogenic fungus Metarhizium anisopliae: the ribotoxin anisoplin. Biol Chem. 2017;398:135-42.

11. Olombrada M, Martínez-del-Pozo A, Medina P, Budia F, Gavilanes JG, García-Ortega L. Fungal ribotoxins: natural protein-based weapons against insects. Toxicon. 2014;83:69-74.

12. Herrero-Galán E, Lacadena J, Martínez-del-Pozo A, Boucias DG, Olmo N, Oñaderra M, Gavilanes JG. The insecticidal protein hirsutellin A from the mite fungal pathogen Hirsutella thompsonii is a ribotoxin. Proteins. 2008; $72: 217-28$

13. Arruda LK, Mann BJ, Chapman MD. Selective expression of a major allergen and cytotoxin, Aspf1, in Aspergillus fumigatus. Implications for the immunopathogenesis of Aspergillus-related diseases. J Immunol. 1992;149:3354-9.

14. Mazet I, Vey A. Hirsutellin A, a toxic protein produced in vitro by Hirsutella thompsonii. Microbiology. 1995;141:1343-8.

15. Liu WZ, Boucias DG, McCoy CW. Extraction and characterization of the insecticidal toxin hirsutellin A produced by Hirsutella thompsonii var. thompsonii. Exp Mycol. 1995;19:254-62.

16. Herrero-Galán E, García-Ortega L, Olombrada M, Lacadena J, Del Pozo ÁM, Gavilanes JG, Oñaderra M. Hirsutellin A: a paradigmatic example of the insecticidal function of fungal ribotoxins. Insects. 2013;4:339-56.

17. Kao R, Davies J. Fungal ribotoxins: a family of naturally engineered targeted toxins? Biochem Cell Biol. 1995;73:1151-9.

18. Ahmad M, Hirz M, Pichler H, Schwab H. Protein expression in Pichia pastoris: recent achievements and perspectives for heterologous protein production. Appl Microbiol Biotechnol. 2014;98:5301-17.

19. Looser V, Bruhlmann B, Bumbak F, Stenger C, Costa M, Camattari A, Fotiadis D, Kovar K. Cultivation strategies to enhance productivity of Pichia pastoris: a review. Biotechnol Adv. 2015;33:1177-93.

20. Rabert C, Weinacker D, Pessoa A Jr, Farías JG. Recombinants proteins for industrial uses: utilization of Pichia pastoris expression system. Braz J Microbiol. 2013;44:351-6.

21. Gurramkonda C, Polez S, Skoko N, Adnan A, Gäbel T, Chugh D, Swaminathan S, Khanna N, Tisminetzky S, Rinas U. Application of simple fed-batch technique to high-level secretory production of insulin precursor using Pichia pastoris with subsequent purification and conversion to human insulin. Microb Cell Fact. 2010;9:1-11.

22. Cunha AE, Clemente JJ, Gomes R, Pinto F, Thomaz M, Miranda S, Pinto R, Moosmayer D, Donner P, Carrondo MJ. Methanol induction optimization for scFv antibody fragment production in Pichia pastoris. Biotechnol Bioeng. 2004;86:458-67.

23. Mallem M, Warburton S, Li F, Shandil I, Nylen A, Kim S, Jiang Y, Meehl M, d'Anjou M, Stadheim TA, Choi BK. Maximizing recombinant human serum albumin production in a Mut(s) Pichia pastoris strain. Biotechnol Prog. 2014;30:1488-96

24. Zhang W, Inan M, Meagher MM. Rational design and optimization of fedbatch and continuous fermentations. Methods Mol Biol. 2007:389:43-64.
25. Cámara E Landes N, Albiol J, Gasser B, Mattanovich D, Ferrer P. Increased dosage of AOX1 promoter-regulated expression cassettes leads to transcription attenuation of the methanol metabolism in Pichia pastoris. Sci Rep. 2017;7:44302.

26. Yang J, Lu Z, Chen J, Chu P, Cheng Q, Liu J, Ming F, Huang C, Xiao A, Cai H, Zhang $L$. Effect of cooperation of chaperones and gene dosage on the expression of porcine PGLYRP-1 in Pichia pastoris. Appl Microbiol Biotechnol. 2016;100:5453-65.

27. Liu Y, Wang Z, Yin Y, Cao Y, Zhao H, Xia Y. Expression, purification, and characterization of recombinant Metarhizium anisopliae acid trehalase in Pichia pastoris. Protein Expr Purif. 2007;54:66-72.

28. Li H, Hui X, Yang S, Hu X, Tang X, Li P, Li S, Yang L, Jing S, Wang Y, Xu A, Wu D. High level expression, efficient purification and bioactivity assay of recombinant human platelet-derived growth factor AA homodimer (PDGF-AA) from methylotrophic yeast. Protein Expr Purif. 2013;91:221-7.

29. Olombrada M, Herrero-Galán E, Tello D, Oñaderra M, Gavilanes JG, Martínez-del-Pozo Á, García-Ortega L. Fungal extracellular ribotoxins as insecticidal agents. Insect Biochem Mol Biol. 2013:43:39-46.

30. van Beek N, Davis DC. Baculovirus insecticide production in insect larvae. Methods Mol Biol. 2016;1350:393-405.

31. Peng G, Xia Y. Expression of scorpion toxin LqhIT2 increases the virulence of Metarhizium acridum towards Locusta migratoria manilensis. J Ind Microbiol Biotechnol. 2014;41:1659-66.

32. Bilgo E, Lovett B, Fang W, Bende N, King GF, Diabate A, St Leger RJ. Improved efficacy of an arthropod toxin expressing fungus against insecticide-resistant malaria-vector mosquitoes. Sci Rep. 2017;7:3433.

33. Fitches EC, Pyati P, King GF, Gatehouse JA. Fusion to snowdrop lectin magnifies the oral activity of insecticidal $\omega$-Hexatoxin-Hvla peptide by enabling its delivery to the central nervous system. PLoS ONE. 2012;7:e39389.

34. Liu SM, Li J, Zhu JQ, Wang XW, Wang CS, Liu SS, Chen XX, Li S. Transgenic plants expressing the AalT/GNA fusion protein show increased resistance and toxicity to both chewing and sucking pests. Insect Sci. 2016;23:265-76.

35. Herrero-Galán E, García-Ortega L, Lacadena J, Martínez-del-Pozo Á, Olmo N, Gavilanes JG, Oñaderra M. A non-cytotoxic but ribonucleolytically specific ribotoxin variant: implication of tryptophan residues in the cytotoxicity of hirsutellin A. Biol Chem. 2012;393:449-56.

36. Yang S, Fitches E, Pyati P, Gatehouse JA. Effect of insecticidal fusion proteins containing spider toxins targeting sodium and calcium ion channels on pyrethroid-resistant strains of peach-potato aphid (Myzus persicae). Pest Manag Sci. 2015;71:951-6.

37. Li WP, Xia LQ, Ding XZ, Lv Y, Luo YS, Hu SB, Yin J, Yan F. Expression and characterization of a recombinant an insect-specific neurotoxin $\omega$-ACTXHv1a in Bacillus thuringiensis. Gene. 2012;498:323-7.

38. Li H, Wang Y, Xu A, Li S, Jin S, Wu D. Large-scale production, purification and bioactivity assay of recombinant human interleukin-6 in the methylotrophic yeast Pichia pastoris. FEMS Yeast Res. 2011;11:160-7.

Ready to submit your research? Choose BMC and benefit from

- fast, convenient online submission

- thorough peer review by experienced researchers in your field

- rapid publication on acceptance

- support for research data, including large and complex data types

- gold Open Access which fosters wider collaboration and increased citations

- maximum visibility for your research: over $100 \mathrm{M}$ website views per year

At BMC, research is always in progress.

Learn more biomedcentral.com/submissions 